\title{
Lymphocytoma cutis on the inguinal region: report of a rare case of benign lymphoproliferative disorder*
}

\author{
Wildson Santos Craveiro Rosa ${ }^{1}$ \\ Iluska Maria Soares de Carvalho ${ }^{1}$
}

\author{
Régio José Santiago Girão ${ }^{2}$ \\ Lana Mayara Meneses Lustosa Vargas ${ }^{1}$
}

DOI: http:/ / dx.doi.org/10.1590/abd1806-4841.20175555

\begin{abstract}
Lymphocytoma cutis, or benign reactive lymphoid hyperplasia, is an inflammatory skin lesion that mimics clinically and histologically malignant lymphoma. Most cases are idiopathic, but they may also be triggered by multiple factors, such as insect bites, tattoos, injections and herpes zoster. Clinically, the lesions are erythematous, soft papules, plaques or nodules, usually located on the upper limbs and face. The diagnosis is mainly based on histopathology and immunohistochemistry. Corticosteroid injections, cryosurgery, PUVA therapy, radiotherapy and surgery can be therapeutic options in cases requiring immediate treatment. To demonstrate an atypical presentation of this tumor, a case lymphocytoma skin on the groin will be reported, describing its diagnosis and treatment.
\end{abstract}

Keywords: Corticosteroids; Hydroxycorticosteroids; Hyperplasia; Pseudolymphoma

\section{INTRODUCTION}

Lymphocytoma cutis, benign reactive lymphoid hyperplasia, or Spiegler-Fendt pseudolymphomas are inflammatory lesions that mimic malignant lymphoma clinically and histologically. They are a rare condition with higher incidence in Caucasian, young (before 40 years of age) females (3:1 ratio). ${ }^{1,2}$

Lymphocytoma cutis is classified according to its lymphoid population, dermal infiltration pattern and associated clinical findings. In 1980, Burg and Braun-Falco proposed a classification based in the architecture of the cutaneous infiltrate, dividing them in T-cell and B-cell models. The T-cell model is characterized by a dense infiltrate in the upper dermis, mimicking mycosis fungoides. This group includes actinic reticuloid, lymphomatoid contact dermatitis and lymphomatoid drug eruption. The B-cell model presents with a nodular infiltrate all through the dermis, as seen in malignant cutaneous B-cell lymphomas. This group includes lymphocytoma cutis, Jessner's lymphocytic infiltration and some insect bite reactions. ${ }^{3}$

Most cases are idiopathic, but lesions may be triggered by multiple factors - such as insect bites, vaccinations, acupuncture, piercings, traumas, tattoos, injections, herpes zoster scars, HIV, drugs, contact with certain allergens, purpuric lichenoid dermati- tis, lichen sclerosus et atrophicus, secondary syphilis, inflammatory morphea, Borrelia burgdorferi, Leishmania donovani or molluscum contagiosum - , that have in common the generation of a more intense lymphocytic reaction in the skin. The most frequently associated drugs are phenytoin, angiotensin converting enzyme inhibitors, antihistamines and, less frequently, bromocriptine and cefuroxime. The lesions are mainly located on the face and upper limbs. ${ }^{2-4}$

Clinically, the lesions appear as soft, erythematous papules, plaques or nodules. ${ }^{5}$

The diagnosis is based on histopathology, clinical features and patient follow-up. The condition is chronic, but is benign and asymptomatic, tending to spontaneous resolution without residual scarring. ${ }^{6,7}$

Considering the challenging and important differential diagnosis, the objective of this study was to report a case of a patient with lymphocytoma cutis on the inguinal region.

\section{CASE REPORT}

A 16-year-old female patient, student, born and resident in Teresina (PI, Brazil), sought medical assistance due to the presence of papules that started to coalesce into a linear, papillomatous tu-

Study submitted on 07.01.2016

Approved by the Advisory Board and accepted for publication on 13.01.2017

* Study conducted at Faculdade Integral Diferencial (Facid-Devry) - Teresina (PI), Brazil.

Financial Support: None

Conflict of Interests: None

1 Department of Medicine of the Faculdade Integral Diferencial (Facid-DeVry) - Teresina (PI), Brazil.

Department of Dermatology at Hospital Getúlio Vargas (HGV) - Teresina (PI), Brazil.

(C2017 by Anais Brasileiros de Dermatologia 
mor on the right inguinal region over the past 2 years (Figure 1).

According to the patient, the lesion was asymptomatic, non-bleeding, and she could not identify triggering factors nor comorbidities. Histopathology revealed a dense, heterogenous lymphomononuclear inflammatory infiltrate, with lymphoid follicles with reactive features and preserved epidermis (Figures 2 and 3).

The histological findings suggested lymphocytoma cutis, however, complementary immunohistochemistry was performed for better assessment. Immunohistochemistry revealed a mixed population of $\mathrm{B}$ lymphocytes (CD20) and T lymphocytes (CD3) (Figures 4 and 5).

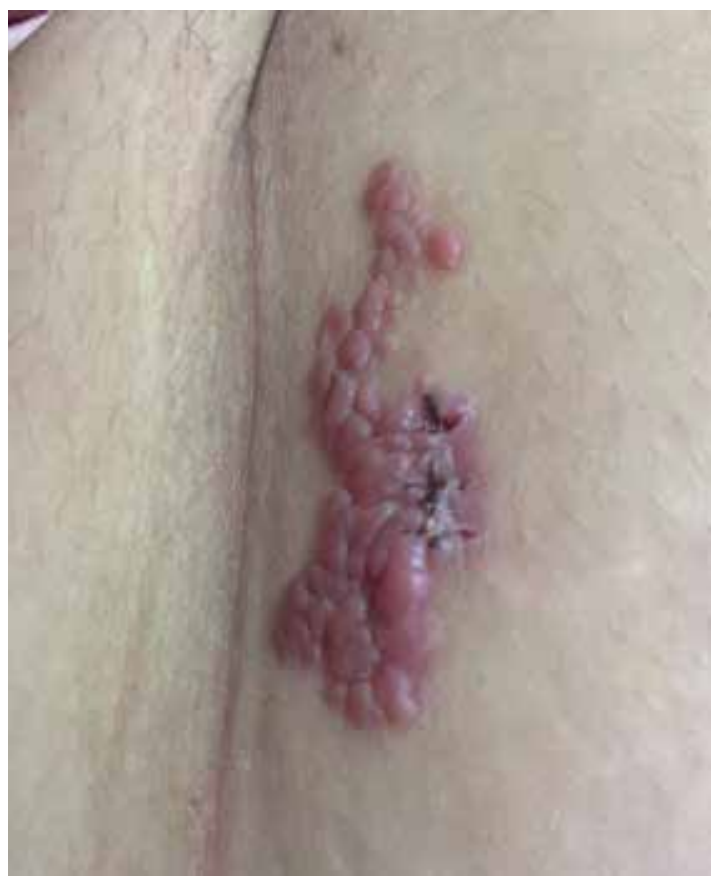

Figure 1: Lymphocytoma cutis (linear papillomatous lesion) on the right inguinal region

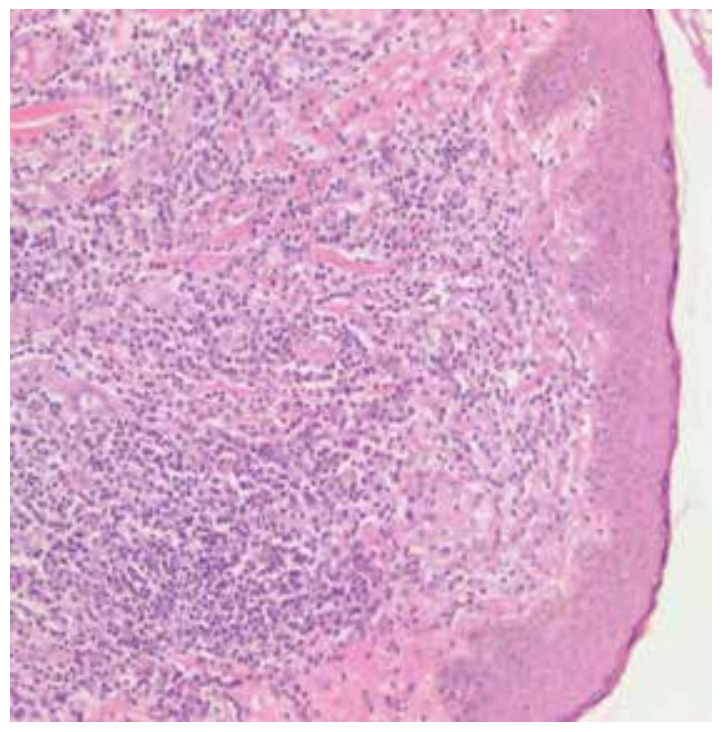

Figure 2: Detail of the lymphoid infiltrate with preserved epidermis (Hematoxylin \& eosin, X200)
The immunohistochemistry's conclusion was of a cutaneous lymphoid infiltrate with the following features: 1) heterogenous lymphoid infiltrate with preserved epidermis, occupying predominantly the superficial dermis in a nodular configuration; 2) mixed inflammatory infiltrate with frequent inflammatory cells including plasma cells, macrophages, eosinophils and multinucleated giant cells (Figure 6).

The association of the morphological features with the immunohistochemical profile favored the diagnosis of lymphocytoma cutis. The patient was referred for surgical excision, with no follow-up.

\section{DISCUSSION}

Lymphocytoma cutis can be either localized, the most common form, or disseminated. ${ }^{8}$ The reported case demonstrated the localized form with a unique presentation: papillomatous, linear, soft, non-scaly, erythematous and varying in diameter $(7 \mathrm{~cm}$ to $10 \mathrm{~cm})$.

Lymphocytoma cutis is traditionally subdivided into "exclusively B-cells" and "exclusively T-cells", however, the majority of

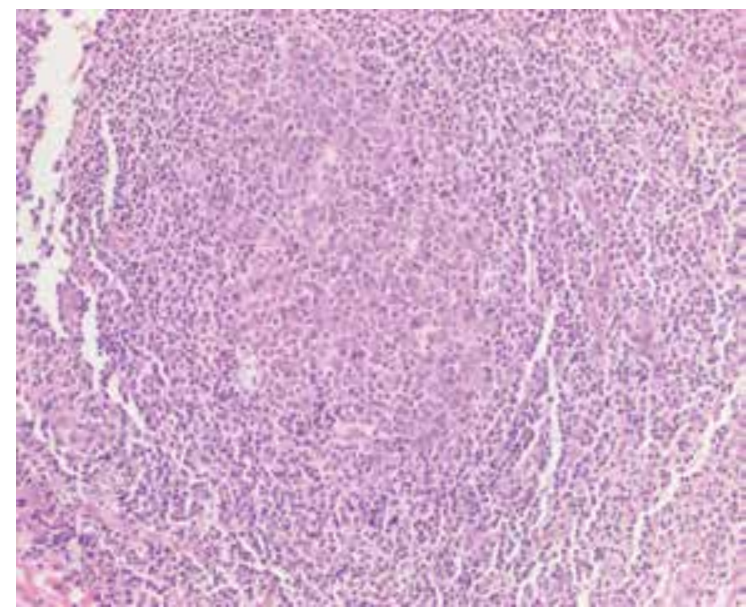

Figure 3: Nodular lymphoid infiltrate with germinal center (Hematoxylin \& eosin, X200)

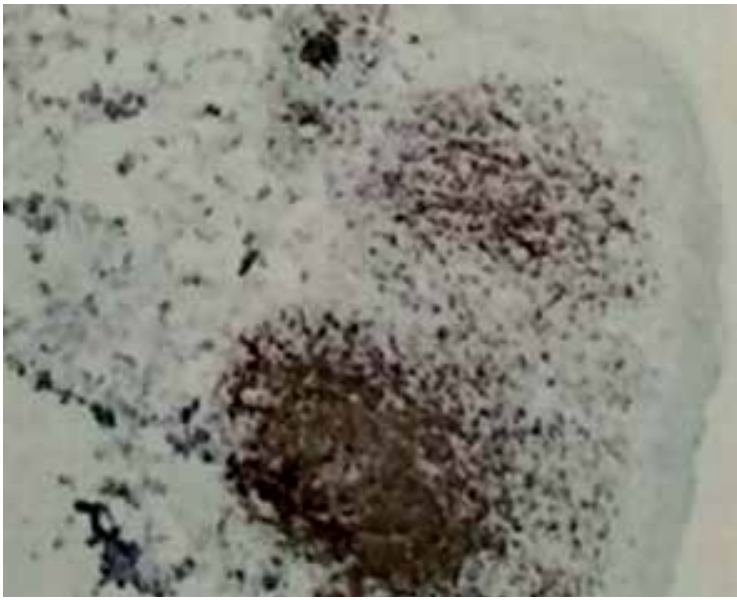

Figure 4: B lymphocyte infiltrate (CD20) on immunohistochemistry 


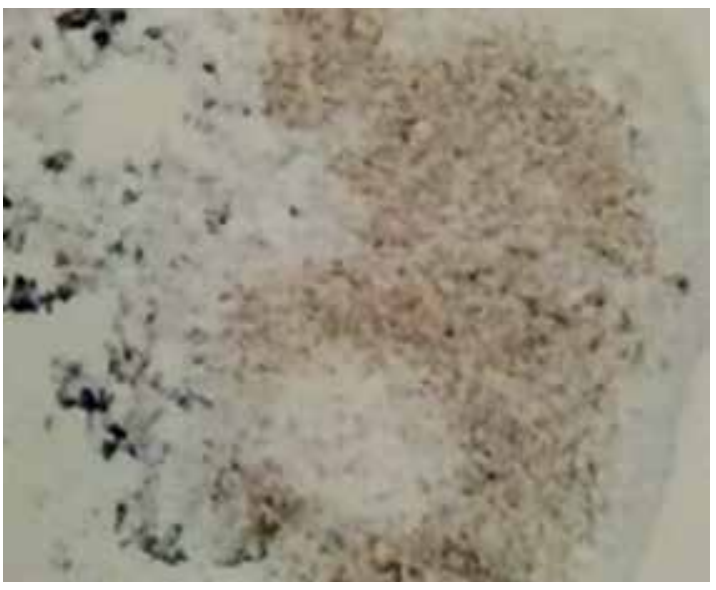

Figure 5: T lymphocyte infiltrate (CD3) on immunohistochemistry

lesions also have histiocytes. In some cases, there are plasma cells and eosinophils, such as in our case. On histopathology, it is characterized by a mixed, nodular or diffuse infiltrate in the papillary and reticular dermis. In this case, there was involvement of the superficial dermis in a nodular configuration and preservation of the epidermis., ${ }^{710}$

The differential diagnosis can be made with angiolymphoid hyperplasia, sarcoid, mycosis fungoides, polymorphous light eruption and cutaneous lymphoma. The latter is the main differential diagnosis, given the different biological behavior, prognosis and therapeutic implications. The differentiation between lymphocytoma cutis and cutaneous lymphoma can be done through a clinical, histological and immunohistochemical analysis. The demonstration of a monoclonal expression of light chains or the absence of detectable immunoglobulin in tumor samples are typical of cutaneous B-cell lymphoma

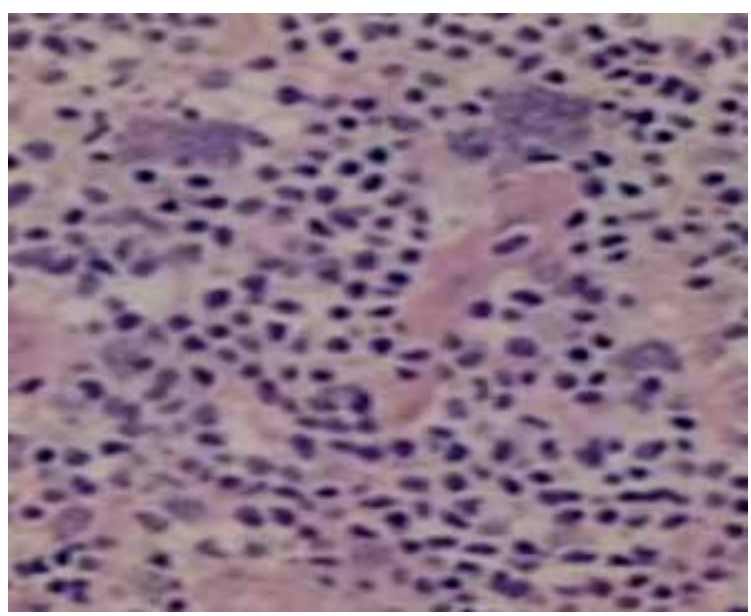

FIGURE 6: Mixed lymphoid infiltrate with inflammatory cells, including plasma cells, macrophages, eosinophils and multinucleated giant cells (Hematoxylin \& eosin, X1000)

and represent the most important criteria for its diagnosis. An accurate diagnosis of these lesions is necessary to guide treatment and for a proper prognosis. Importantly, in sporadic cases, there is possibility of the appearance of a cutaneous lymphoma in the same areas where lymphocytoma cutis was previously diagnosed. Cutaneous lymphoma has a worse prognosis and treatment response. ${ }^{1,7}$

A broad analysis allows the classification of this case as idiopathic lymphocytoma cutis, according to the history clinical aspect, histopathology and immunohistochemistry. ${ }^{2}$

There is some controversy in literature regarding treatment. Corticosteroid injections, cryosurgery, PUVA therapy, radiotherapy and surgery can be therapeutic options in cases needing immediate treatment. In our case, the patient was treated with surgery. ${ }^{3,6}$

\section{REFERENCES}

1. Cerroni L, Borroni RG, Massone C, Chott A, Kerl H. Cutaneous B-cell pseudolymphoma at the site of vaccination. Am J Dermatopathol. 2007;29:538-42.

2. Cerroni L, Kerl H. Diagnostic immunohistology: cutaneous lymphomas and pseudolymphomas. Semin Cutan Med Surg. 1999;18:64-70.

3. Khaled A, Sassi S, Fazaa B, Ben Hassouna J, Ben Romdhane K, Kamoun MR. Primary cutaneous marginal zone B-cell lymphoma: clinical and histological aspects. Pathologica. 2009;101:18-20.

4. Watanabe R, Nanko H, Fukuda S. Lymphocytoma cutis due to pierced earrings. Cutan Pathol. 2006;33:16-9.

5. LeBoit PE. "Magic bullets" in immunohistochemistry. Am J Dermatopathol. 2002;24:518-20.

6. Van Vloten WA, Willemze R. The many faces of lymphocytoma cutis. J Eur Acad Dermatol Venereol. 2003 Jan; 17(1):3-6.

7. Colli C, Leinweber B, Müllegger R, Chott A, Kerl H, Cerroni L.. Borrelia Burgdoferi associated lynphocitoma cutis: clinicopathologic, immunophenoypic and molecular study of 106 cases. J Cutan Pathol. 2004;31:232-40.

8. Plaza JA, Comfere NI, Gibson LE, Colgan M, Davis DM, Pittelkow MR, et al. Unusual cutaneous manifestations of B-cell chronic lymphocytic leukemia. J Am Acad Dermatol. 2009;60:772-80.
9. Arai E, Shimizu M, Hirose T.A review of 55 cases of cutaneous lymphoid hyperplasia: reassessment of the histopathologic findings leading to reclassification of 4 lesions as cutaneous marginal zone lymphoma and 19 as pseudolymphomatous folliculitis. Hum Pathol. 2005;36:505-11.

10. Leinweber B, Colli C, Chott A, Kerl H, Cerroni L. Differential diagnosis of cutaneous infiltrates of $B$ lymphocytes with follicular growth pattern. Am J Dermatopathol. 2004;26:4-13.

CORRESPONDENCE ADDRESS:

Wildson Santos Craveiro Rosa

Avenida João de Paiva, 125, Centro

64290-000 Altos, PI

Brazil

E-mail:wildson-santos125@hotmail.com

How to cite this article: Rosa WSC, Girão RJS, Carvalho IMS, Vargas LMML. Lymphocytoma cutis on the inguinal region: report of a rare case of benign lymphoproliferative disorder. An Bras Dermatol. 2017;92(5 Suppl 1): 98-100. 